\title{
IVF remains in legal limbo
}

\section{The British government, first in the field with a coherent policy on research in innovatory human} biology, is lapsing into sloth by its seeming willingness to let legislation be delayed.

WHAT (if anything) should be done to regulate research and medical practice in human embryology? For most of this decade, that has been a lively and contentious public issue. It will remain so for many years to come, expecially as late entrants to the controversy declare their interests. (The Vatican, which issued its instruction on in vitro fertilization (IVF) only a few weeks ago, is a special case; its comment on current disputes may have been slow in coming, but its general position has been wellknown.) In the circumstances, it may be inevitable that the pattern of regulation is muddled and confusing. In most places, most of the United States, for example, laissez faire seems to be the guiding principle. Elsewhere, as in Australia, there are islands of zealousness (the state of Victoria) in a sea of relative indifference. In West Germany, it seems that the cards are being dealt for what will be a battle between the federal justice ministry and professional interests, while in Britain, where the government three years ago welcomed the report of its Warnock committee, promised legislation is still not forthcoming.

The British problem is especially instructive because the issues to be decided have been drawn with admirable clarity. The Warnock committee decided that IVF techniques are a welcome means of treating infertility which nevertheless prompts legal questions about parentage (where eggs or sperm are derived from sources other than the nominal parents), but that public anxiety about the uses that might be made in laboratories of artificially fertilized human embryos requires that research projects in this field should be regulated, preferably intelligently, and that breaches of the regulations should be criminal offences. Both the government and the scientific community in Britain accepted these conclusions; the government promised legislation within a year. Now, three years later, the oddly named Voluntary Licensing Authority (for human IVF and embryology) is complaining (see p.92) that both its own work and research in human embryology are being hampered by the continuing lack of legislation.

\section{Legislation}

The circumstances are curious, to say the least. The Voluntary Licensing Authority is the creation of two nominally autonomous organizations, the Medical Research Council and the Royal College of Obstetricians and Gynaecologists; the licences it has issued to about 30 centres have no statutory force. Even so, there is no reason to suppose that centres practising IVF have chosen not to announce their existence. Helpfully, the "authority" also now provides a list of research projects at the licensed centres. The vast majority are directed towards the improvement of the efficiency of IVF techniques (still only 11 per cent per menstrual cycle); the two exceptions (out of 32) are angled at the early detection of chromosome abnormalities, which is part of the same theme. But experience has also shown that some centres active in the field decline to make spare embryos available to others because of the legal uncertainties that persist, which is "an unfortunate waste of unique and precious material". That is another good reason why the uncertainty should be removed.

But how? The British government's position, outlined in a discussion paper last December, is that it wishes to act deliberately and comprehensively, even if that implies delay. The betting is that a bill will not appear until October 1988, if then. Meanwhile, the danger persists that public policy will be hijacked by some group of private parliamentarians. (Next week, we shall be publishing a characteristically impassioned statement to just such a group by Dr Erwin Chargaff, the molecular biologist.) Part of the trouble is that the government has been unlucky in its short-stay health ministers; Mr Barney Hayhoe, appointed only a few months after Warnock, was conscientiously at odds with the government's intentions, his successor, Ms Edwina Currie, seems more interested in helping people to stop smoking cigarettes and to take up jogging. But the lawyers are also letting their search for perfection cloud their judgement. IVF and the other innovations in human embryology on which decisions are required do not constitute an integral field of public policy in which model laws once written will stand for the rest of time. Rather, they are extensions of present practice that provoke awkward questions in unrelated fields. (Are IVF children legitimate for the purposes of inheritance? Do their nominal parents have a duty to tell them if one gamete or another is derived from some other source? What kinds of research projects are permissible now? And when more is known of the process of development?)

\section{Frameworks}

Pragmatic as it is, the British government probably does not differ much from others in its readiness to let these question lie for the time being, knowing as it must that they cannot be debated without raising all kinds of other awkward questions. the rights and wrongs of abortion law, for example. But there is an urgent need to regularize present practice in IVF (for which the Warnock proposals are sufficient) and to allow generally acceptable research to proceed within a framework that both researchers and the world at large can understand, but which can be changed with circumstances. That is one task.

Another might be to ban the use of the word "pre-embryo". used by the voluntary authority as a synonym for a fertilized human ovum not yet implanted in a uterus. Put simply, this usage is a cop-out, a way of pretending that the public conflict about IVF and other innovations in human embryology can be made to go away by means of an appropriate nomenclature. The fact is that a fertilized human egg is as much deserving of being called an embryn as is a fertilized frog's egg. The essence of the controversy orer the new human embryology centres rests on the question when, in the course of development, an embryo commands the legal respect to which free-living people are entitled. The issue turns on the necessity of implantation for development, on analogies (necessarily less persuasive) with the randomness of what happens in real-life procreation and on arguments about the reality of the soul (which to many is a figment of the human imagination). Even those who share the British self-styled voluntary authority's eagerness that IVF should be more widely and efficiently practised will acknowledge that, on the issue of nomenclature, the Vatican is philosophically the more consistent. 